\title{
Forehead Flap For Nasal Reconstruction Our Experience With 40 Cases \\ Mohammad Shakeel ${ }^{1}$, Mohamad Imran ${ }^{2}$, AzharKhan $^{3}$, Muzafar Ahmad ${ }^{4}$ Munaza Shafi ${ }^{5}$, Mudasar Ahad ${ }^{6}$, \\ ${ }^{I}$ Associate Professor, MaxillofacialSurgery, Skims Medical College Srinagar \\ 2,3,4,5.. Registrar, Maxillofacial Surgery, Skims Medical College \\ ${ }^{6}$ Assistant Professor,Department Of Orthodontics ,Skims Medical College Srinagar
}

\begin{abstract}
Objectives: To assess the efficacy and efficiency of forehead flap in reconstruction of nasal defects.

Methodology: This study was carried out on 40 patientsof either sex who required reconstruction of nasal defects of different etiologies.

Results And Conclusion: Forehead flap is a reliable technique for reconstruction of nasal defects of varied origin . Keywords: Supratrochlear Artery, Forehead Flap, Pedicle, Local Flaps.
\end{abstract}

\section{Introduction}

Forehead flap is one of the commonly used pedicle flaps for reconstruction of nasal defects ${ }^{1}$.Its use for reconstruction of nasal defects dates back to early days of civilization as mentioned in the Hindu holy book "Susruta Veda" in 800 B.C ${ }^{2}$.The flap is based on supratrochlear/supraorbital vessel. This flap is commonly used to reconstruct the acquired and congenital nasal deformities.

Its qualities include abundant tissue availability, which allows resurfacing of the entire nasal subunit, its excellent match in colorand skin texture. Above all it has robust vascularity and low donor site morbidity. Forehead flap has the advantage of being locally available and has potential to resurface large nasal cutaneous defects ${ }^{3,4}$. This flap has consistent vascular anatomy, abundantblood supply $\&$ favorable arc of rotation. It can coverthe soft tissue defects $^{5}$ by providing a thin musclebulk as well as intact mucosal lining ${ }^{6}$.In this paper, we describe our own experiences with different types offorehead flaps in the management of different nasal defects of varied origin.

\section{Methods}

The study included 40 patients with different nasal defects resulting from burns, bear maul injury,infection,excision of naviand post traumatic defects aged between 20 to 60 years, of either sex.

Patients under radiation therapy to the forehead region, previous surgery or trauma to the forehead region and medically compromised patients who cannot tolerate general anesthesia were excluded. Written informed consent obtained from all patients/parents/attendants, for inclusion in surgical procedure and use of the data for research purpose.

The following parameters were analyzed: the patient's age, sex, cause of injury that led to the reconstruction, the number of sub-units involved in the nose,the type of graft used, thesurgical methods used for reconstruction of the nasal lining,the number of surgeries per patient and postoperativecomplications.

\section{Surgical technique}

Preoperatively the supraorbital and supra trochlear arteries were identified and marked by digital palpation.The defect was marked along with the anticipated skin resection and the measurements were transferred to the donor region using suture cover as template. The flap was harvested superficial to the frontalis muscle in the distal part and together with this muscle close to the periosteum, in the proximal part, in order to protect the vessels. After harvesting, the flap was thinned when needed tomatch the thickness of the tissue from the defect. The flap was sutured on the defect and the donor site closed near the midline. 


\section{Results}

The study included 17 males and 23 females mostly in the age group of 41-50 years (Figure 1). The most common etiology of nasal defects was burn injury $(n=15)$ followed by trauma $(n=11)$, excision of navus $(n=6)$, bear maul $(n=5)$ and infection ( $n=3)$ (Figure 2).In most of the patients $(n=16)$, only one nasal subunit was involved.(Figure 3).Full-thicknessdefects were present in $60 \%$ of the patients and all such cases were reconstructed using folded forehead flap. Structural support was necessary in 7 ( 2.8\%) patients (Figure 4). Cartilage washarvested from the conchal bowl (29\%) and costal cartilage(43\%).The bone graft was required in



Figure 1.Age distribution of patients.

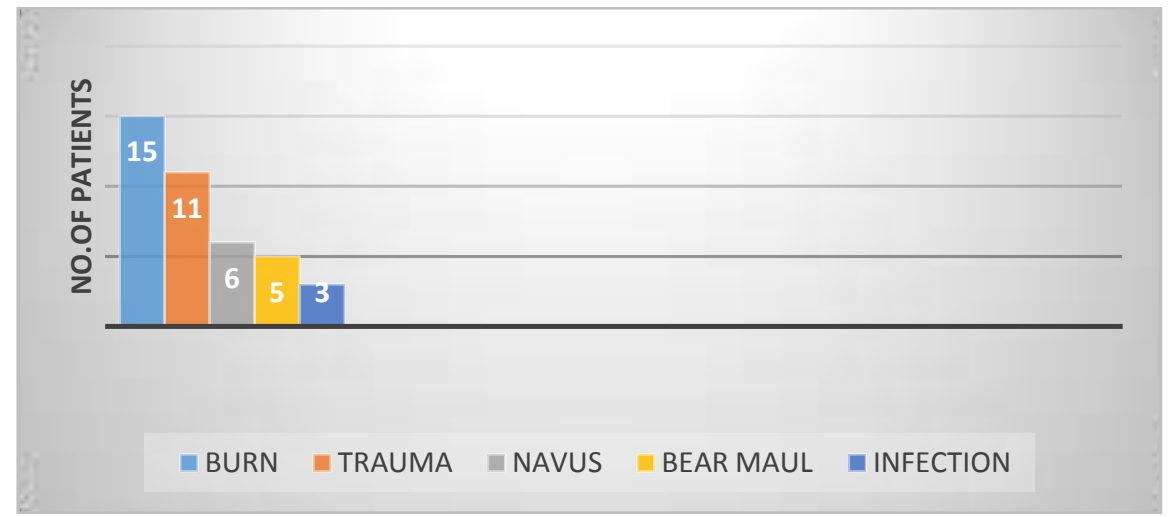

Figure 2.Etiology of nasal defects.

two patients which was obtained from rib in one patient and from iliac crest in another patient. A posterior incision was given to harvest the graft in all cases.

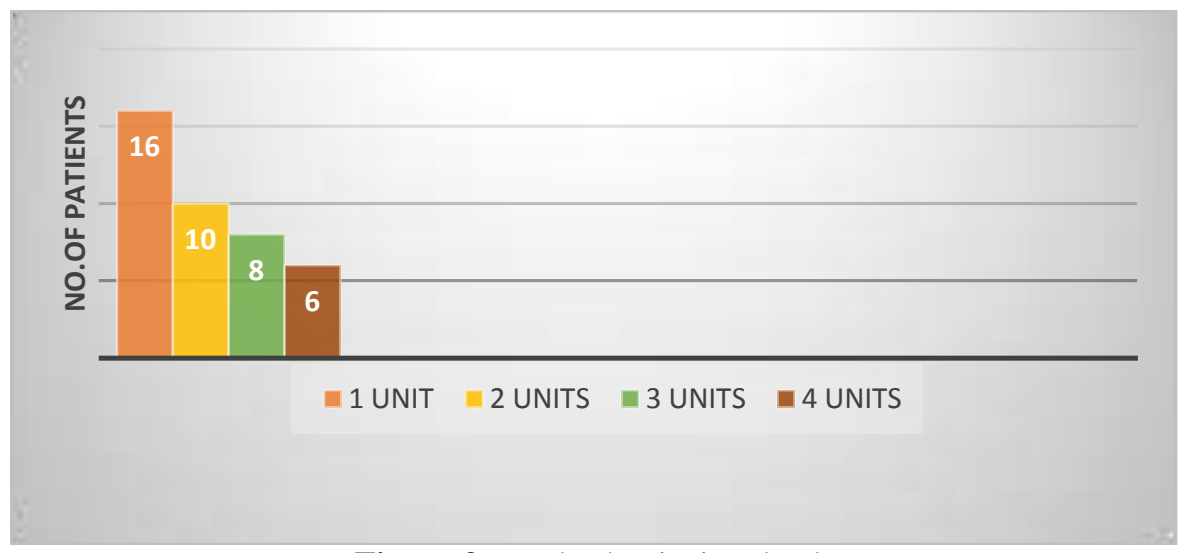

Figure 3.Nasal subunits involved. 


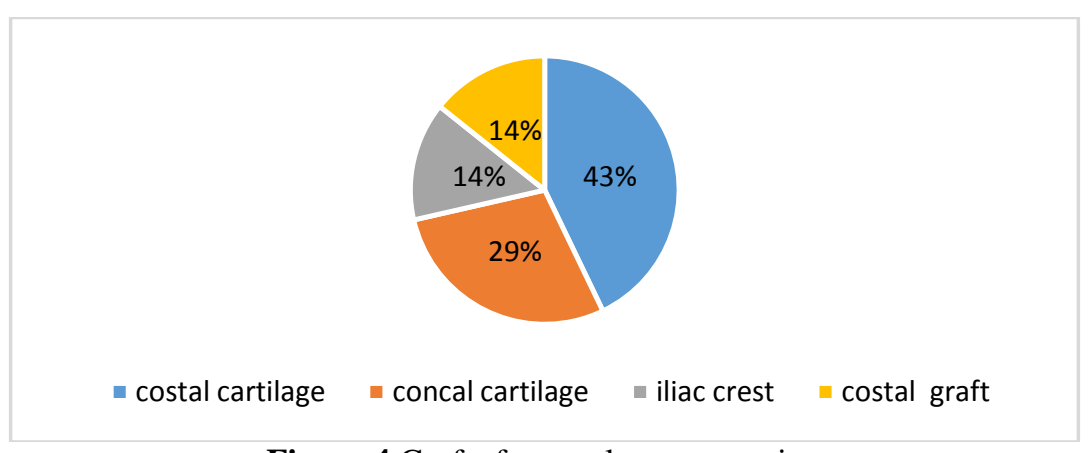

Figure 4.Grafts for nasal reconstruction

The flap pedicle was designed ipsilateral to the defect in 18 patients and contralateral in 22 patients.Closureof the forehead was most commonly accomplished by primary closure.

Complications (Figure 5) were few and were managed properly.

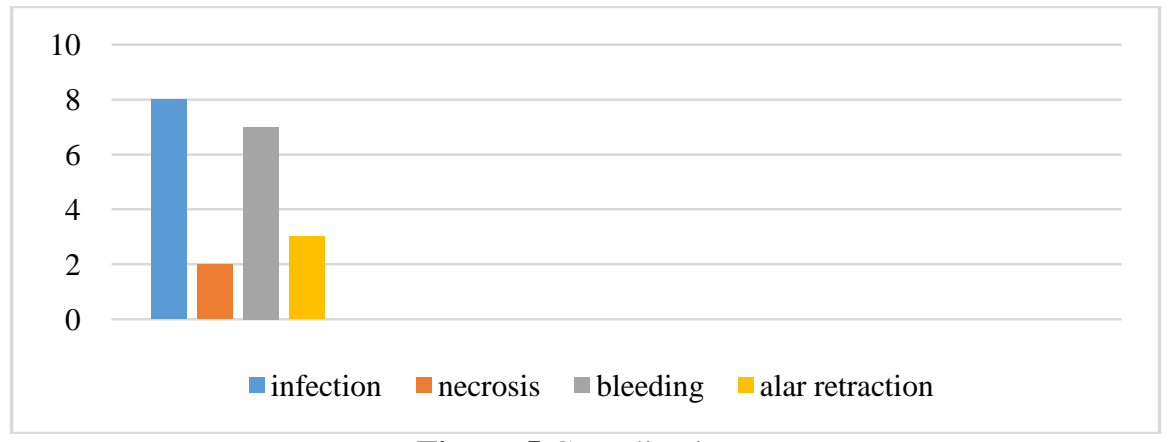

Figure 5.Complications

Immediately after surgery ,some patients $(\mathrm{n}=7)$ had post op bleeding from the flap pedicle. It was managed with local hemostatic agents. One patients developed post operativeinfectiononthe cartilage donor site which was treated with oral antibiotic. Following the second stage, two patients had superficialand proximal necrosisdue toaggressive thinning. Both were treated with wound care andhealed uneventfully.

Complication after the third stage occurred in three patient, who developed alar retraction and were very much unsatisfied with the treatment and never returned back to us .Despite complications,almostall patients had excellent functional and aesthetic results.

\section{Discussion}

The nose is one of the mostdifficultchallenge for reconstructionafter surgical defects. Closure options are individualized for eachpatient and defect. For large defects on the distal nose, however,options that achieve a good functional and aesthetic outcomeare limited. When wounds are extensive, deep, and or involvemissing cartilage or mucosal lining, no other repair can approachthe consistency and predictability of the PFF.

The subunit principle is an important concept in reconstruction ${ }^{7}$.If a defect involves greater than $50 \%$ of a subunit,excising the residual skin and resurfacing the entire subunit mayyield better aesthetic outcomes.Thisprinciple, however, is not absolute ${ }^{8}$ Excellent results may beachieved with partial subunit replacement. In this study, threepatients had partial subunit resections (hemitip) withexcellent results. Fourteen patients had completesubunit excision. Among those, seven (50\%) also had partialexcision of an additional subunit.

The PFF should be thought of as a robust surface coveringthat can provide soft tissue thickness but not structural support.Nasal lining and structural cartilage are the infrastructuresthat must be either intact, supplemented, and or restored priorto the PFF$^{9}$. Options to restore small mucosal defects $(<1 \mathrm{~cm})$ include a turnover hinge flap, turndown of a forehead flapextension, a full-thickness skin graft (FTSG), and bipediclevestibular skin advancement flap. Larger lining restoration mayrequire a turnover forehead flap, FTSG vascularized by an overlyingPFF, or intranasal lining flaps (septal mucoperichondrialhinge flap, composite septal chondromucosal pivotal flap $)^{10,11}$.Intranasal mucosal flaps are difficult to perform without conscioussedation or general anesthesia. Other 
options above, however,may be successfully executed under local anesthesia.Cartilage grafts are either structural (native cartilagepresent but additional needed for support) or restorative (replacingwhat was removed).

Structural functions of cartilage include:1) preventing tissue contraction and distortion, 2) bracing heavyflap tissue, 3) maintaining airway patency and augmenting theinternal nasal valve, and 4) achieving contour support (i.e. nasaltip graft for better projection). Donor sites for cartilage graftsmay include the antihelix (scaphoid fossa) and the conchal bowlfrom one or both ears ${ }^{12,13}$.

Conchal cartilage is ideal forgrafts that demand more curvature, substance, and rigidity and work better to avoid nasal valve or lobule collapse, and for collumela and tip projection. Sculpting and beveling of the graft is often necessary to achievethe desired thickness, contour, shape, and tapered edges. Thisshould be carefully done since cartilage is a fragile structure andmay break during the process. Cartilagegrafts may be safely harvested under local anesthesia ${ }^{14}$.Postoperative pain after forehead flap is variable.However, if cartilage grafting was performed then the auriculardonor site is predictably more painful after surgery than theforehead flap donor site. For this reason, we routinely injected long acting local anesthetic(Bupivacaine) after closing the ear donor site in addition to postoperativeanalgesics.

Whether the forehead flap should be completed in two or threestages is a matter of debate. Folded PFFs that restore nasal liningabsolutely require three stages. The first stage harveststhe flap and folds it to provide both nasal lining and surface covering.

The second stage ( 3 weeks) retains the pedicle, but opensthe PFF margin at the alar rim to debulk excess tissue and toinsert cartilage support. The third stage (6 weeks) divides thepedicle and sculpts the flap further for completion. PFFs that arenot folded to restore lining may also be staged in 3 sessions ${ }^{15}$.

The first stage incorporates cartilage support and PFF creationand inset. The second stage ( 3 weeks) elevates the flap partiallyand debulks excess tissue to improve contour. The third stage (6weeks) then divides the pedicle. The main advantage of thethree-stage PFF is the ability to sculpt a thin, supple contour inpatients with delicate nose tips and ala. Two stage flaps in thesepatients often result in bulbous, thick contours. Disadvantages ofthe three-stage PFF are the delay in pedicle division and theextra procedure. However, the three-stage procedure is morereliable in smokers as the flap contains muscle and has a very

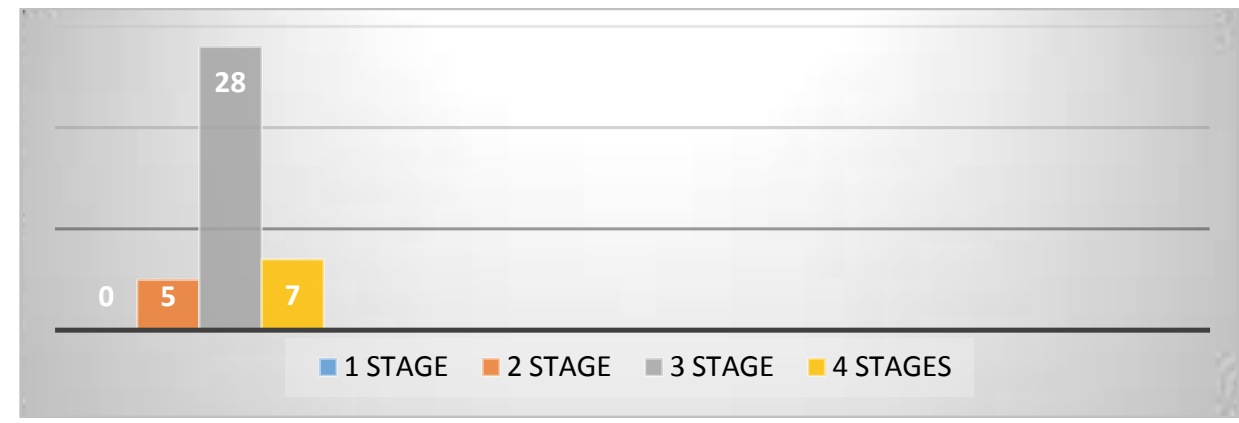

Figure 6.No. of surgical stages in a patient

robust blood supply. It may also be of benefit in cases where aprofound underlying lining and cartilaginous reconstructionhave been performed, as the frontalis provide an extremely richanastomotic vascular network ${ }^{16}$.

Most of the patients $(n=28)$ required three surgical stages in this study( Figure 6). Twenty four (24) patients were submitted to foldedforehead flap, two required a more aggressive thinning, and one neededrepositioning of the flap due to distal necrosis.

For most patients, the two-stage approach is safely performedbydebulking the distal portion of the flap at the firststage. As long as a thin layer of subdermal fat is preserved, thenthesupratrochlear artery is protected $^{16}$.Thinning of the proximalportion of the flap is usually performed at the time of pedicledivision and should be carefully done. In our study, five (5) patients underwent two stage surgery.

Pedicle side is an important consideration when designingthe PFF. Traditionally, the pedicle has been designed contralateralto the defect to minimize its torsion. However, a narrowpedicle (1 to $1.5 \mathrm{~cm})$ allows an ipsilateral design withoutconcerns about significant torsion ${ }^{17}$. Moreover, the ipsilateraldesign increases the flap reach. We performed 18 ipsilateral and 22 contralateral flap designs without any difficulty in either procedure.

Attempting to completely close the forehead donor site isnot advisable. The forehead is approximated as much as possiblewithout tension. However, when significant tension is noted, theremaining wound should heal by second intention $^{18}$. All our case had primary closure of donor site without any complication. 
Potential complications of the PFF include bleeding,pain, poor scarring, infection, dehiscence, distortion of free marginsand flap necrosis ${ }^{19}$. In this study, despite the higher rate of complicationscompared to previous studies performed by dermatologicsurgeons, complications were minor and treatable. Furthermore,all patients had optimal to excellent functional and aestheticresults.

\section{Conclusion}

The PFF is a valuable flap in the repair of large and deep nasal defects of different etiologies. Its reliableblood supply, color, and textural qualities and resultant contourwarrant strong consideration for its application. Restoring theentire subunit should be considered. Optimal results, however,may be achieved with hemi subunit repair. With good surgicalplanning, measures for patient comfort, and meticulous technique,the PFF may be safely performed in an outpatient settingand can achieve unique restoration of the nose.

\section{Illustration Of Few Cases}

Case 1.This is a 40 year old male with left alar defect due to burn injury.The defect was repaired with forehead flap in three stages (fig.7).

Case 2 .A 55 year old lady with navus on the dorsal nose extending on lateral nasal wall on right side. Good results achieved with forehead flap(fig.8)

Case 3.A 26 year old female with navus at the root of nasal dorsum managed with forehead flap (fig.9).

Case 4. A 4 year old male child with burn injury of nose . Patient was managed with median forehead flap with good results (fig.10).

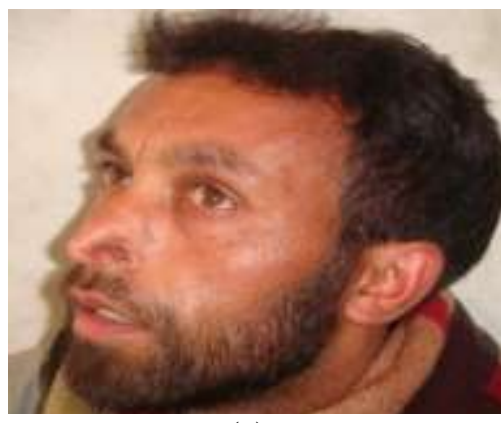

(a)

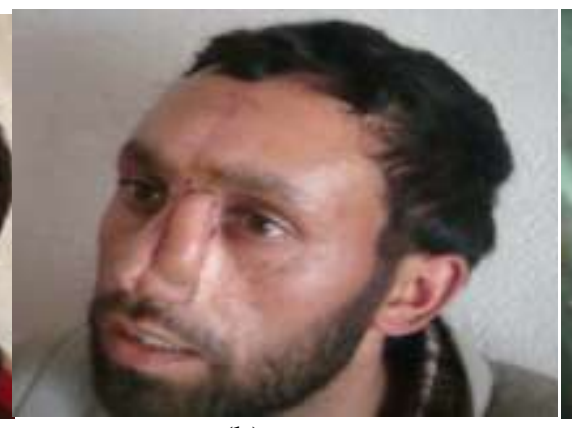

(b)

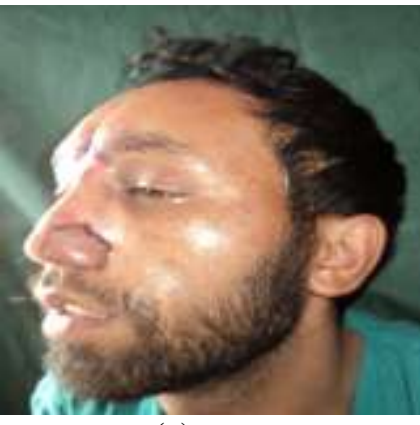

(c)

Figure 7.Composite defect of left nasal ala (a) preoperative pic (b) forehead flap in place (c) after pedicle detachment.

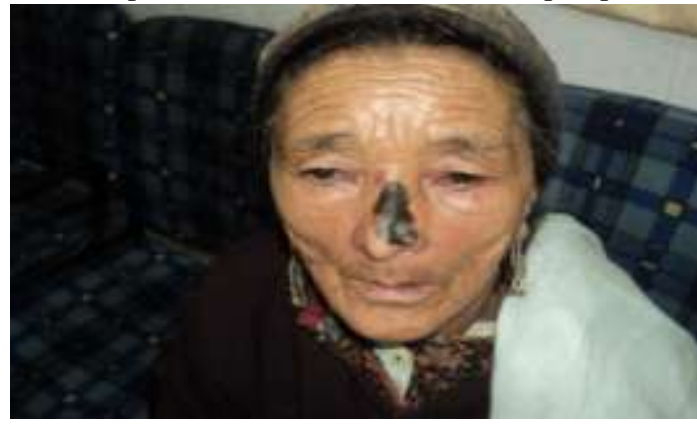

(a)

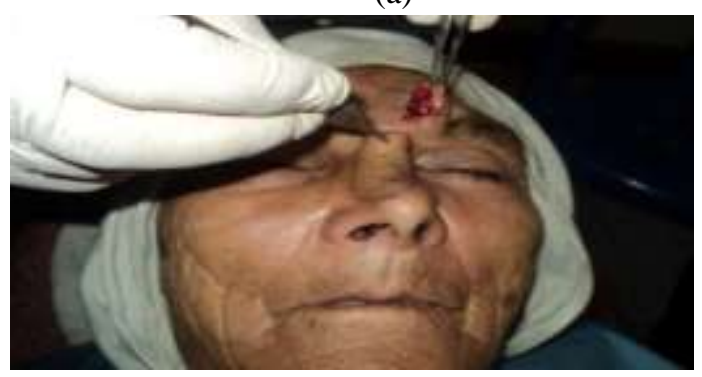

(c)

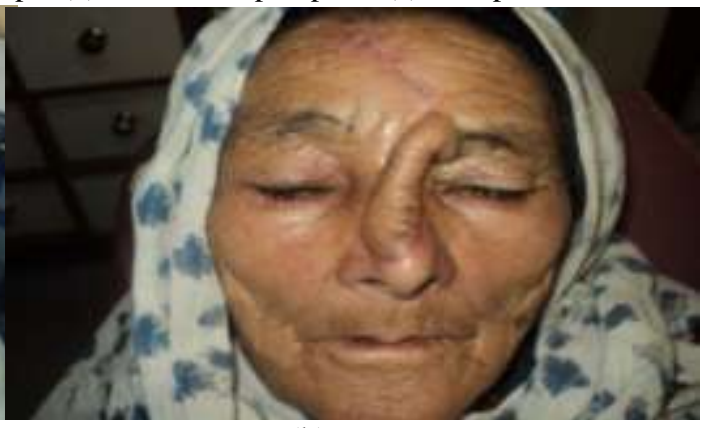

(b)

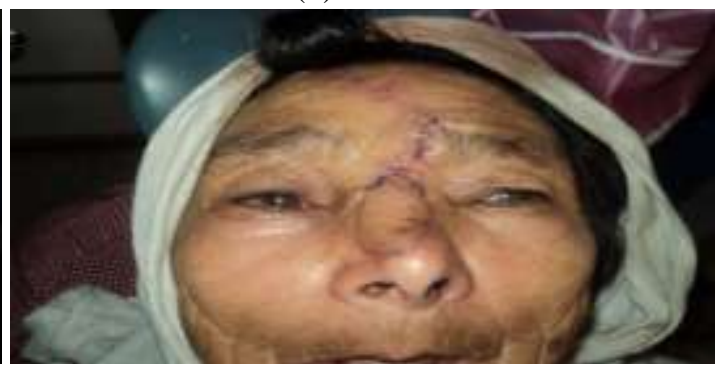

(d) 
Figure 8. A big nevus on nasal dorsum (a) preoperative view (b) forehead flap in place (c) pedicle being detached (d) one week post pedicle detachment.

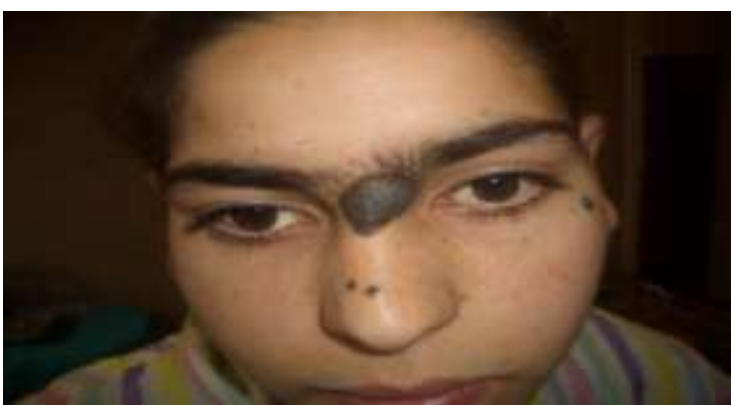

(a)

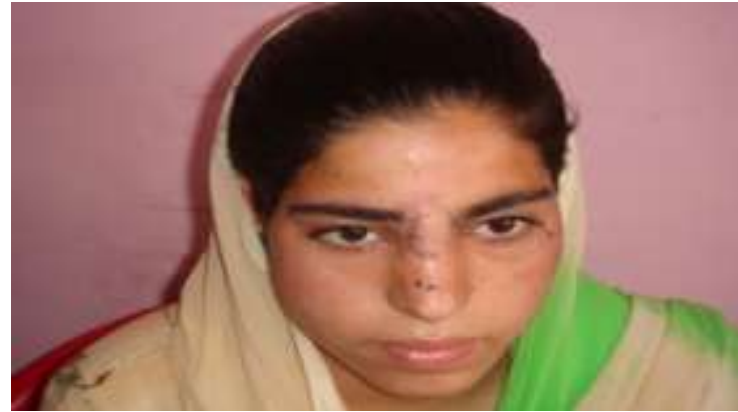

(b)

Figure 9. Navus at the root of nasal dorsum (a) preoperative picture (b) post operative picture

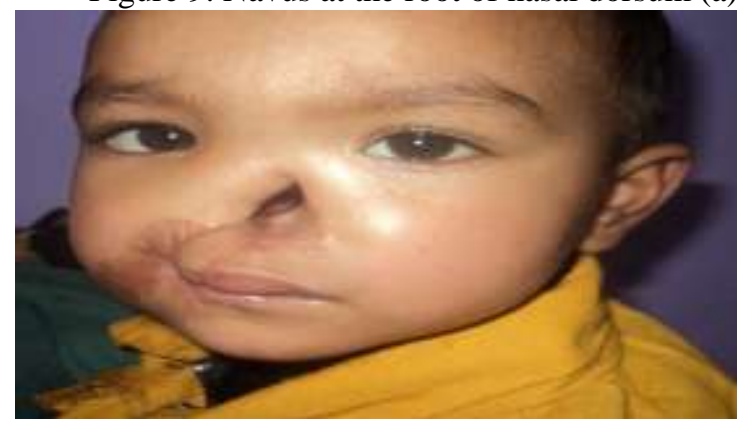

(a)

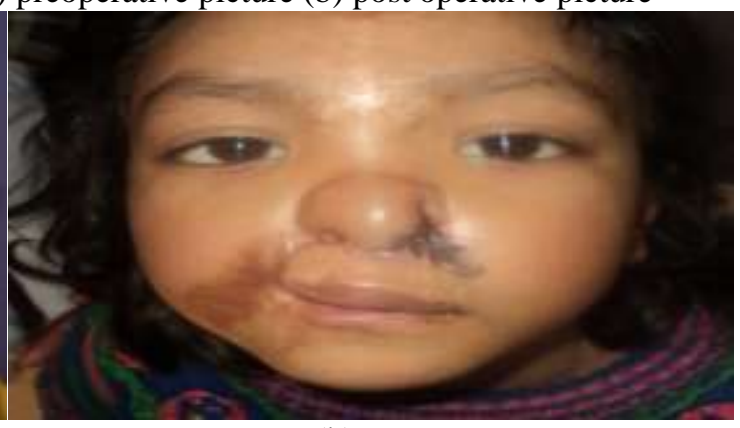

(b)

Figure 10. Burn injury with loss of most of the nasal structure (a) preoperative (b) one month postoperative picture.

\section{References}

[1]. Anastassov GE, Schwartz S, Rodriguez E. Buccinatormyomucosal island flap for postablativemaxillofacial reconstructions: a report of 4 cases.JOralMaxillofac Surg. 2002;60:816-21.

[2]. Bhishagratna KKL, ed. SushrutaSambita. Calcutta, Bose, 1907-1916.

[3]. Sadhotra LP, Singh M, Raje R. Reconstruction of complete palatal defect with a forehead flap: A case report.Indian J PlastSurg .2003;36:120-122

[4]. Millard DR Jr.Total reconstructive rhinoplasty and a missing link. PlastReconstr Surg. 1966;37:167-83

[5]. Shah AA, Malik WM. Head and neck reconstruction: a 3 years experience. Ann King Edward Med Coll .1999; 5:19-21.

[6]. Warraich RA, Cheema SA. Head and neck reconstructive options for soft tissue defects.. Ann King Edward Med Coll .2001; 7: 11-13.

[7]. Burget GC, Menick FJ. The subunit principle in nasal reconstruction. PlastReconstr Surg. 1985;76(2):239-47.

[8]. Rohrich RJ, Griffin JR, Ansari M, Beran SJ, Potter JK. Nasal reconstruction beyond aesthetic subunits: a 15 -year review of 1334 cases. PlastReconstr Surg. 2004;114(6):1405-16; discussion 1417-9.

[9]. Burget GC. Aesthetic restoration of the nose. ClinPlast Surg. 1985;12(3):463-80.

[10]. Boyd CM, Baker SR, Fader DJ, Wang TS, Johnson TM. The forehead flap for nasal reconstruction. Arch Dermatol. 2000;136(11):136570.

[11]. Baker S. Internal lining. In: Baker S, Naficy S, editors. Principles of nasalreconstruction. St Louis: Mosby, 2002 p. 31-46.

[12]. Ratner D, Skouge JW. Surgical pearl: the use of free cartilage grafts innasal alar reconstruction. J Am AcadDermatol. 1997;36(4):622-4.

[13]. Byrd DR, Otley CC, Nguyen TH. Alar batten cartilage grafting in nasalreconstruction: functional and cosmetic results. J Am AcadDermatol.2000;43(5 Pt 1):833-6.

[14]. SurgCosmetDermatol 2014;6(1):1724.

[15]. Cerci FB, Nguyen TH

[16]. Sage RJ, Leach BC, Cook J. Antihelical cartilage grafts for reconstructionof mohs micrographic surgery defects. Dermatol Surg.

[17]. 2012;38(12):1930-7.

[18]. Menick FJ. A 10-year experience in nasal reconstruction with the threestageforehead flap. PlastReconstr Surg. 2002;109(6):1839-55; discussion1856-61.

[19]. Burget GC, Menick FJ. Nasal support and lining: the marriage of beautyand blood supply. PlastReconstr Surg. 1989;84(2):189-202.

[20]. 17. Menick FJ. Aesthetic refinements in use of forehead for nasal reconstruction:the paramedian forehead flap. ClinPlast Surg. 1990;17(4):607-22.

[21]. Nguyen TH. Staged interpolation flaps. In: Roher TE, Cook JL, NguyenTH, Mellete Jr, JR, editors. Flaps and grafts in dermatologic surgery. NewYork: Elsevier, 2007. p. 91-105.

[22]. Little SC, Hughley BB, Park SS. Complications with forehead flaps innasal reconstruction. Laryngoscope. 2009;119(6):1093-9. 